\title{
Giant Intraosseous Synovial Cyst with Intraarticular Communication with the Ankle Joint in Longstanding Rheumatoid Arthritis
}

YASSER EMAD AMIN, MD, PhD, Rheumatology and Rehabilitation Department, Faculty of Medicine, Cairo University, Cairo, Egypt; Rheumatology and Rehabilitation Department, Dr. Erfan and Bagedo General Hospital, Jeddah, Saudi Arabia; YASSER RAGAB, MD, PhD, Radiology Department, Faculty of Medicine, Cairo University, and Radiology Department, Dr. Erfan and Bagedo General Hospital; NASHWA EL-SHAARAWY, MD, Rheumatology and Rehabilitation Department, Suez Canal University, Ismailia, Egypt; AHMED KAMAL, MD, Orthopedics Department, Faculty of Medicine, Cairo University, Orthopedics Department, Dr. Erfan and Bagedo General Hospital, Jeddah, Saudi Arabia. Address correspondence to Dr. Y. Amin, Faculty of Medicine, Cairo University, Rheumatology and Rehabilitation, Cairo 12613, Egypt; E-mail: yasseremad68@yahoo.com. J Rheumatol 2011;180-1; doi:10.3899/jrheum.111029

The term "intraosseous synovial cyst" is used to designate the epiphyseal cyst-like lesions seen in a variety of clinical settings. Extraarticular synovial cysts in rheumatoid arthritis (RA) have rarely been documented in case reports. The same is true for giant intraosseous synovial cysts with intraarticular communication. We describe an adult case of RA with uncontrolled disease, involving a giant intraosseous synovial cyst in the lower end of the tibia and communicating with the ankle joint.

A 56-year-old woman with longstanding aggressive RA presented with chronic pain around the ankle joint of 6 months' duration. After control of synovitis with a combination of disease-modifying antirheumatic drugs, the patient still complained of pain around the right ankle and the lower end of the tibia. Magnetic resonance imaging (MRI) was done to further evaluate the cause of the pain. A contrast-enhanced MRI study showed evidence of a giant intraosseous synovial cyst at the lower end of the tibia and other evidence of destructive changes in the ankle joint in the form of erosive bone changes and hypertrophic synovial membrane (pannus) in postcontrast images (Figure 1).

To our knowledge, an intraosseous synovial cyst in RA is

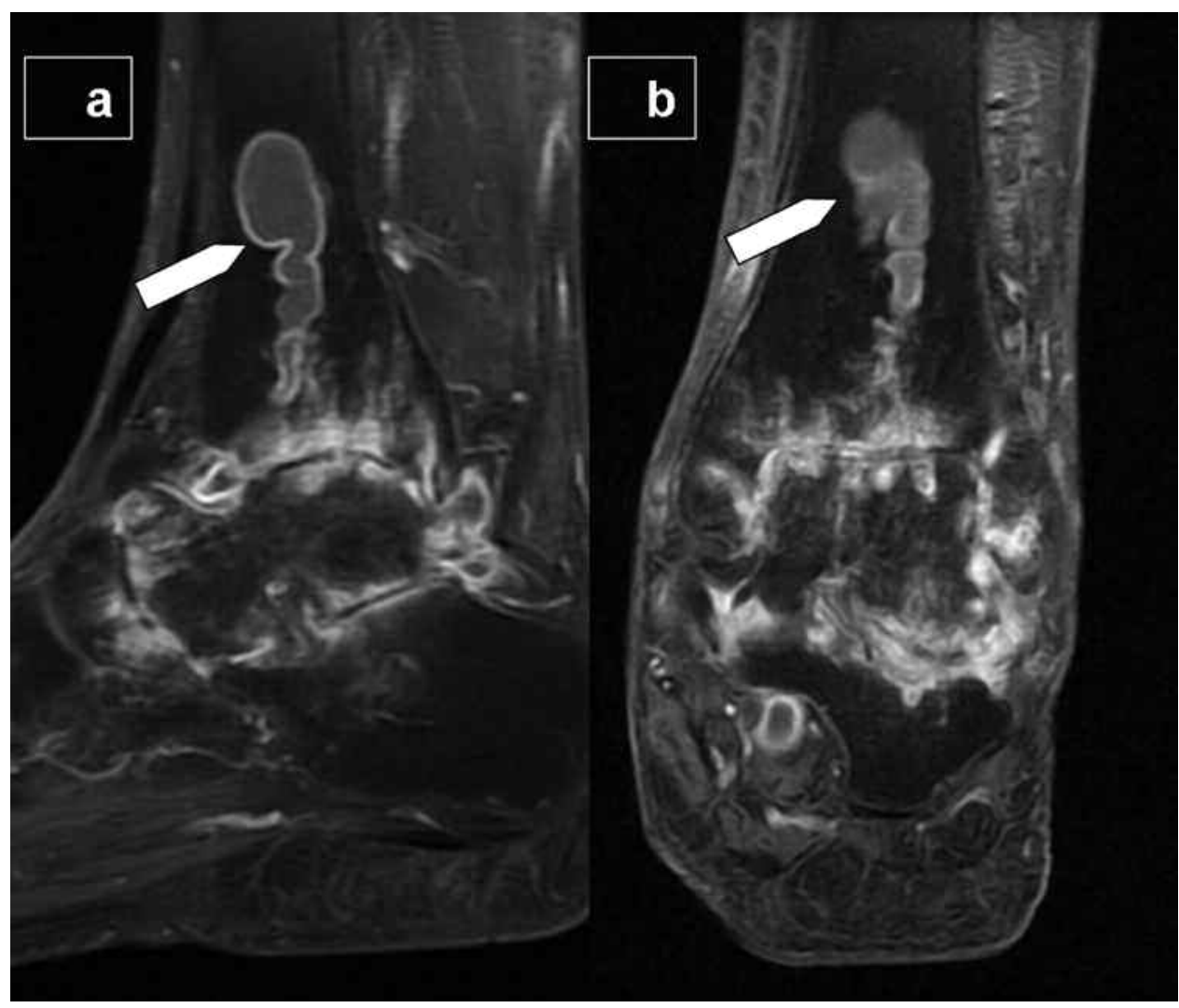

Figure 1. Postcontrast fat saturation coronal (a) and sagittal (b) sections for the right ankle joint show chronic arthritis and synovitis changes with cartilage erosions, subarticular bone pseudocysts, tibialis posterior tenosynovitis, and giant intraosseous synovial cyst in the tibia (arrows). 
rare. Lohse, et al $^{1}$ reported a woman in whom a 4-cm cyst-like lesion developed in the left tibia 18 years after the onset of RA. Henning, et $a l^{2}$ reported giant intraosseous tubular synovial cysts of the knee joint.

A few case reports described extraarticular synovial cysts at different joints in RA. A bicipital synovial cyst in systemiconset juvenile idiopathic arthritis (JIA) ${ }^{3}$ has been described. Another 3 cases of JIA presented acute swelling of the upper arms, and MRI revealed large synovial cysts with intraarticular connection ${ }^{4}$. In addition, Dell'Era, et al described a case of RA with multiple extraarticular synovial cysts ${ }^{5}$.

\section{REFERENCES}

1. Lohse A, Carbillet JP, Onimus M, Stevenel F, Toussirot E, Wendling D. Giant intraosseous cyst-like lesions in rheumatoid arthritis: report of a case. Joint Bone Spine 2003;70:67-70.

2. Henning E, König C, Duda S. Giant tubular synovial cysts of the knee joint in rheumatoid arthritis [German]. Rofo 2002;174:905-6.

3. Shimizu M, Yokoyama T, Wada T, Yachie A. Bicipital synovial cyst in systemic-onset juvenile idiopathic arthritis. J Pediatr 2010;157:168.

4. Kirino Y, Ihata A, Shizukuishi K, Hama M, Takase K, Suda A, et al. Multiple extra-articular synovial cysts complicated with rheumatoid arthritis. Mod Rheumatol 2009;19:563-6.

5. Dell'Era L, Vercellesi P, Forzenigo LV, Carnelli V, Corona F. Synovial cyst in juvenile idiopathic arthritis. Clin Rheumatol 2008;27 Suppl 2:S43-5. 